\title{
Tympanogram and Audiogram Presentation after Tympanomastoidectomy Surgery Using Musculus Temporalis Fascia Profunda Graft and Composite Graft
}

\author{
Sandrianto Lande, ${ }^{1}$ Riskiana Djamin ${ }^{1}$, Sutji Pratiwi Rahardjo ${ }^{1}$ \\ ${ }^{1-3}$ Associate Professor of Department of Otrhynoolaryngology-Head and Neck Surgery, \\ Hasanuddin University School of Medicine, Makassar, Indonesia
}

\begin{abstract}
In recent decades, there has been an increase in the use of composite graft in the closure of the tympanic membrane perforation. The aim of this research is to know the change of tympanogram and audiogram presentation after tympanomastoidectomy surgery using musculus temporalis fascia profunda graft and composite graft. Experimental research was being conducted on 22 Otitis Media Suppurative Chronic patients without cholesteatoma such as 14 patients using musculus temporalis fascia profunda graft and 8 patients using composite graft. The Audiometric tests were being administered twice, before and after tympanomastoidectomy surgery, in other hand tympanometry test was being performed after surgery. Data analysis using independent-t test, paire-t test, and chi square test. The research has shown that the Pure Tone Audiometry post-surgeries were being found higher on composite graft $(68,4)$ in comparison with musculus temporalis fascia profunda graft $(55,1)$, but statistically non-significant $(p>0,05)$. On the contrary, on fascia graft group was being found significantly higher 1,47 than amplitudo composite graft $(0,87)$, statistically significant $(\mathrm{p}<0,001)$. Clinical meaning of using musculus temporalis fascia profunda graft is better than composite graft in terms of hearing and tympanic membrane elasticity.
\end{abstract}

Key words: musculus temporalis fascia profunda graft, composite graft, tympanomastoidectomy

\section{Introduction}

The tympanic membrane is a living tissue located in the middle ear. The first component of the middle ear that is useful for receiving sound waves is the tympanic membrane, also known as the eardrum. Sound waves vibrate the tympanic membrane through a small series of auditory bones, namely malleus, incus and stapes ${ }^{1}$. The time limit of 2 months varies from country to country. WHO set a time limit of 2 weeks. Most ENTKL specialists take a 3-month limit ${ }^{2}$.

Chronic suppurative otitis media (CSOM) is divided into two namely chronic otitis media without cholestatoma and with cholesteatoma, both of which are distinguished by looking at the inflammatory process, the presence or absence of cholesteatoma and the location of the tympanic membrane perforation with different management. The incidence of otitis media is influenced by various factors including age, nutrition, socio- economic level, immunity factors and the frequency of suffering from upper respiratory tract infections ${ }^{3}$

Closure of the tympanic membrane is very important to prevent recurrent infections, restore hearing, and protect the structure of the middle and inner ear. Timpanoplasty can be performed with a variety of different graft techniques and materials ${ }^{4,5}$. In recent decades, there has been an increase in the use of composite graft in the closure of the tympanic membrane perforation. Timpanoplasty using a graft composite as tympanic membranes have a better success rate in the treatment of CSOM, due to the low need for graft nutrition, suitable for difficult conditions, in subtotal perforations, adhesive otitis media, revision surgery and tubal dysfunction ${ }^{6,7}$.

Many autologists use composites as a graft material because of their good stability, resistance to negative middle earpressure and noteasy postoperativeperforation. 
Regular control after tympanomastoidectomy prevents reperforation from Chavan et al., ${ }^{8}$ Kumar et al., ${ }^{9}$ and Previous research by Tao et $\mathrm{al}^{10}$ found that temporal graft fascia has more advantages such as being easier to extract, more quantity, relatively transparent, thinner and more flexible, but its elasticity strength as a low tympanic membrane makes it far more susceptible to negative pressure from the middle ear. Based on the background above, this study aims to determine changes in the image of tympanogram and audiogram postoperative tympanomastoidectomy using deep temporalis muscular graft fascia and composite graft.

\section{Materials and Method}

Research Location and Time

The study was conducted at the Wahidin Sudirohusodo Makassar hospital at the central ENT-KL and COT clinic, which began in July - September 2019.

Research Design and Variables

This research is an experimental research (prospective observational study) with a design using groups with simple randomization. The research variables consisted of: independent variables (CSOM), dependent variables (pure tone audiometry (PTA) and Timpanogram), control variables (composite graft and temporalis muscular graft fascia), and intermediate variables (perforation and closure of the tympanic membrane perforation).

\section{Population and Sample}

The study population was Chronic Rhinosinusitis sufferers who met the inclusion criteria who came to the ENT-KL Polyclinic at the General Hospital. Dr. Wahidin Sudirohusodo and RS Network in Makassar.

\section{Method of collecting data}

In the ear with otore, first clean the secretions with an applicator and suction. Investigations were carried out: laboratory, plain mastoid photographs, temporal bone CT scans and PTA. Then the sample was divided into 2 treatment groups, namely: Group 1 using composite graft (temporalis and composite muscular fascia) and Group 2 using temporal muscular graft fascia, and tympanomastoidectomy and postoperative procedures.

\section{Data analysis technique}

The data collected is then processed and analyzed using the SPSS for windows program. The statistical test used was a t test to compare audiological results before surgery and after surgery between graft composites (temporal muscular fascia and composite) and temporal muscular graft fascia with tympanomastoidectomy techniques, the level of significance used was $\beta=0.20$. All analysis results are displayed in tabular or graphical form accompanied by an explanation.

\section{Results}

An experimental study (prospective observational study) has been conducted with a design using a group with simple randomization to determine changes in the image of tympanogram and audiogram postoperatively of tympanomastoidectomy using deep temporalis musculature fascia graft and composite graft. The highest tympanogram type obtained in this study is type A with sample 12 (54.54\%) compliance value 0.3-1.6, As type with sample 7 (31.81\%) compliance value $<0.3$, and type of Ad sample number 3 (13.63\%) compliance value> 1.6 (Table 1$)$.

Table 1. Type of Tematogram Post Timpanomastoidectomy Surgery

\begin{tabular}{|l|l|l|l|}
\hline No & Tipe Timpanogram & $\mathrm{N}$ & $\%$ \\
\hline 1 & Tipe Ad & 3 & 13,63 \\
\hline 2 & Tipe As & 7 & 31,81 \\
\hline 3 & Tipe A & 12 & 54,54 \\
\hline
\end{tabular}

The use of bone gap water (ABG) with graft fascia obtained a value of $<10 \mathrm{db}$ of $5(35.71 \%), 10-15 \mathrm{db}$ of $5(35.71 \%)$ and $>15 \mathrm{db}$ of $4(28.57 \%)$. In the use of composite graft, there was a water bone gap (ABG) with a value of $<10 \mathrm{db}$ as much as $1(12.5 \%), 10-15-15$ as many $(25 \%)$ and $>15 \mathrm{db}$ as much as $5(62.5 \%)$ (Table 2$)$ 
Table 2. Air Bone Gap (ABG) Pasca Operasi Berdasarkan Jenis Graft

\begin{tabular}{|l|l|l|l|l|l|}
\hline No & Air Bone Gap (ABG) & \multicolumn{2}{|l|}{ Graft Fascia Muskulus Temporalis Profunda } & \multicolumn{2}{l|}{ Graft Komposit } \\
\hline & & Total & $\%$ & Total & $\%$ \\
\hline 1 & $<10$ & 5 & 35,71 & 1 & 12,5 \\
\hline 2 & $10-15$ & 5 & 35,71 & 2 & 25 \\
\hline 3 & $>15$ & 4 & 28,57 & 5 & 62,5 \\
\hline 4 & Total & 14 & 100 & 8 & 100 \\
\hline
\end{tabular}

The hearing threshold is based on PTA preoperative tympanomastoidectomy. For hearing values 26-40 db sample size 1 (4.54\%), 41-60 db sample size 7 (31.81\%), 61-80 db sample size 7 (31.81\%) and > 81db sample size 7 (31.81\%). While the hearing threshold postoperative tympanomastoidectomy obtained a hearing value of $26-40 \mathrm{db}$ sample size $6(27.27 \%), 41-60 \mathrm{db}$ sample size $8(36.36 \%), 61-80 \mathrm{db}$ sample size $5(22.72 \%)$ and $>81 \mathrm{db}$ of sample size $3(13.63 \%)$ (Table 3$)$.

Table 3. Hearing Examination Based on Pure Tone Audiometry (PTA) Pre and Post Thrombomastoidectomy Surgery

\begin{tabular}{|l|l|l|l|l|l|}
\hline \multirow{2}{*}{ No } & \multirow{2}{*}{ Ambang Dengar } & Pre Operasi & \multicolumn{3}{|l|}{ Post Operasi } \\
\cline { 3 - 6 } & & $\mathbf{N}$ & $\%$ & $\mathbf{N}$ & \% \\
\hline 1 & $26-40 \mathrm{db}$ & 1 & 4,54 & 6 & 27,27 \\
\hline 2 & $41-60 \mathrm{db}$ & 7 & 31,81 & 8 & 36,36 \\
\hline 3 & $61-80 \mathrm{db}$ & 7 & 31,81 & 5 & 22,72 \\
\hline 4 & $>81 \mathrm{db}$ & 7 & 31,81 & 3 & 13,63 \\
\hline 5 & Total & 22 & 100 & 22 & 100 \\
\hline
\end{tabular}

Comparison of PTA by graft type shows that Preoperative PTA was found to be higher in composite graft (74.0) than in deep temporalis muscular fascia (65.5), but not statistically significant ( $p>0.05)$. Postoperative PTA was found to be higher in the composite graft (68.4) than in the deep temporalis muscular fascia (55.1), but not statistically significant $(\mathrm{p}>0.05)$ (Table 4$)$.

Table 4. PTA Comparison by Graft Type

\begin{tabular}{|l|l|l|l|l|l|l|}
\hline No & Variabel & Graft & N & Mean & SD & p \\
\hline 1 & PTA Preoperasi & Fascia & 14 & 65,5 & 22,1 & 0,379 \\
\hline & & Komposit & 8 & 74,0 & 19,6 & \\
\hline 2 & PTA Post Operasi & Fascia & 14 & 55,1 & 19,6 & 0,165 \\
\hline & & Komposit & 8 & 68,4 & 23,1 & \\
\hline
\end{tabular}

Independent-t test 
Comparison of preoperative and postoperative PTA showed that in the graft fascia group, it was found that postoperative PTA was significantly lower than preoperative PTA, which was 65.5 compared to 55.1 ( $\mathrm{p}<0.05$ ). In the composite graft group, postoperative PTA was found (68.4) lower than preoperative PTA (74.0), but not statistically significant ( $>0.05)$ (appendix, Table 5).

Table 5. Comparison of Preoperative and Postoperative PTA

\begin{tabular}{|l|l|l|l|l|l|l|}
\hline No & Graft & Variabel & $\mathbf{n}$ & Mean & SD & p \\
\hline 1 & Fascia & PTA preoperasi & 14 & 65,5 & 22,1 & 0,014 \\
\hline & & PTA post operasi & 14 & 55,1 & 19,6 & \\
\hline 2 & Komposit & PTA preoperasi & 8 & 74,0 & 19,6 & 0,303 \\
\hline & & PTA post operasi & 8 & 68,4 & 23,1 & \\
\hline
\end{tabular}

Paired-t test

\section{Discussion}

This study showed that postoperative pure tone audiometry (PTA) was found to be higher in composite graft compared to deep temporalis muscular fascia, but not statistically significant. Whereas in the graft fascia group, post operative amplitude was significantly higher than composite graft amplitude, and was statistically significant. In the study the most samples were found in the age group of $08-20$ years with 10 samples $(45.45 \%)$ followed by the age group of 21-40 years with 6 samples $(27.27 \%)$ and the age group 41-60 years each as many as 6 samples $(27.27 \%)$, the number of samples in adults and parents is less than in the age of children and adolescents.

Most sex in this study were women with a ratio of 1.8: 1 compared to men. The total sample of men was 8 samples (36.36\%) and women contained 14 samples $(63.63 \%)$. Based on the size of the perforation, obtained subtotal perforation of $13(59.09 \%)$ and total perforation of $9(49.90 \%)$. The main factors contributing to the area of tympanic membrane perforation are chronic infection, impaired tubal function and a history of allergies This study uses 2 types of graft, namely composite graft and deep temporalis musculature graft fascia. The number of graft composites used was $8(36.36 \%)$ and temporalis fascia graft as many as 14 (63.63\%), more widely used compared to graft composites. The use of temporal fascial grafts in subtotal perforations is most commonly used in tympanomastoidectomy operations, with success rates between $93 \%$ and $97 \%$. But in recent decades, there has been an increase in interest by using cartilage graft (composite) as the main alternative.

Research conducted in India by Santhanakrishnan et al, 5 also used more temporalis graft 23 samples $(54.76 \%)$ and graft composite as many as 19 samples (45.23\%). Santhanakrishnan et al (2017), using deep temporalis graft fascia to cover small and subtotal perforations, while for large (total) perforations using graft composites. Temporalis fascia graft is an excellent graft material for closure of the tympanic membrane perforation accompanied by increased hearing.

The results of the tympanogram type from this study showed that the highest tympanogram type was type A as many as $12(54.54 \%)$, followed by As type tympanogram as much as $7(31.81 \%)$ and tympanogram type Ad as much as 3 (13.63\%). The state of pressure in the middle ear, tympanic membrane integrity and mobility of auditory bones can be evaluated after tympanomastoidectomy surgery. Different results are 
obtained from the two types of graft used. The results of tympanogram using temporalis graft were better than that of composite graft. Compliance of the tympanic membrane and ocular system under various positive and normal pressure conditions is better in deep temporalis muscular graft fascia. It can easily be understood that compliance the maximum tympanic membrane will be reached when the air pressure on both sides is balanced or equal ${ }^{10-12}$.

Based on the degree of hearing loss and deafness, this study was divided into conductive type hearing loss, sensorinueral type hearing loss and mixed type hearing loss. In patients with CSOM who treated Wahidin Sudirohusodo Hospital and RSPTN Hasanuddin University Makassar obtained hearing loss and conductive type deafness as many as 14 samples $(63.63 \%)$, hearing loss and mixed type deafness were 8 samples (36.36\%) and hearing loss and sensorinueral deafness is absent. In a study in India conducted by Kumar et all $^{9}$, it was slightly different where it only took hearing impairment and conductive deafness with a total sample of 46. From research conducted at Wahidin Sudirohusodo General Hospital and RSPTN UNHAS it was found that the types of hearing loss and deafness were highest in patients is a conductive type of hearing loss.

In this study, it was found that postoperative PTA using temporalis muscular graft fascia was 14 (63.63\%), composite graft was 8 (36.36\%). Using the Paired t-test found in the graft fascia group, it was found that postoperative PTA was significantly lower than PTA Pre surgery, which was 65.5 compared to 55.1 $(\mathrm{p}<0.05)$. In the composite graft group, postoperative PTA was found (68.4) lower than preoperative PTA (74.0), but not statistically significant ( $p>0.05)$. Using preoperative Independent PTA t-test was found to be higher in composite graft (74.0) than in deep temporalis muscular fascia (65.5), but not statistically significant ( $>0.05$ ). Postoperative PTA was found to be higher in composite graft (68.4) than in deep temporalis muscular fascia (55.1), but not statistically significant ( $p>0.05$ ). In the preoperative PTA examination results obtained for the hearing threshold value of 26-40 $\mathrm{db}$ sample size 1 (4.54\%), 41-60 db sample size 7 (31.81\%), 61$80 \mathrm{db}$ sample size $7(31.81 \%)$ and $>81 \mathrm{db}$ of sample size 7 (31.81\%). While post-operative PTA obtained results for the hearing threshold value $26-40 \mathrm{db}$ sample size 6 (27.27\%), 41-60 db sample size 8 (36.36\%), 61$80 \mathrm{db}$ sample size $5(22.72 \%)$ and $>81 \mathrm{db}$ sample size $3(13.63 \%)$. There was an improvement in the results of postoperative audiometry examination at the hearing threshold of 26-40db for 5 samples, 41-60db for 1 sample, $61-80 \mathrm{db}$ for 2 samples and $>80 \mathrm{db}$ for 4 samples.

In this study showed that in the deep temporalis muscular fascia, PTA Air Bone Gap $<10 \mathrm{db}$ of 5 samples (35.71\%), $10-15 \mathrm{db}$ of 5 samples $(35.71 \%)$ and $>$ $15 \mathrm{db}$ of 4 samples $(28.57 \%)$, while those using graft composites obtained $<10 \mathrm{db}$ of 1 sample $(12.5 \%)$, 10 $15 \mathrm{db}$ of 2 samples $(25 \%)$ and $>15 \mathrm{db}$ of $5(10 \%)$. From the results of our research at Wahidin Sudirohusodo General Hospital Makassar and RSPTN UNHAS using temporalis graft fascia graft, the water bone gap (ABG) was improved compared to those using graft composites. In this study the amplitude comparison results can be seen by using 2 different types of graft. This study used 22 samples in which 14 patients used deep muscularis fascia graft and 8 used composite graft. From the results of postoperative tympanomastoidectomy, type A with a sample size of $12(54.54 \%)$, then type As with a sample size of $7(31.81 \%)$ and type Ad with a sample size of $3(13.63 \%)$. Postoperative amplitude was found to be significantly higher in the deep temporalis muscle graft fascia of 1.43 compared to composite graft, which was $0.80(\mathrm{p}<0.05)$.

Using the Paired t-test obtained in the fascia graft group, the postoperative amplitude was significantly higher 1.47 compared to the composite graft amplitude of 0.87 , statistically significant $(p<0.001)$. From our research at RSUP Wahidin Sudirohusodo Makassar and RSPTN UNHAS using temporalis graft fascia graft results obtained tympanometry with better amplitude compared to using graft composites. There was a very significant increase before and after surgery. In this study there are limitations of the study, namely: not carried out monitoring in a sufficient period of time in the growth of the graft both temporal fascia and composite graft, the number of samples is limited, and no examination of PTA and tympanometry 6 months postoperatively.

\section{Conclusions and Recommendations}

Researchers concluded that the use of temporalis muscular graft fascia was better than composite graft in 
terms of hearing enhancement (PTA). Tympanometry and elasticity of the tympanic membrane using temporalis muscular graft fascia are better in terms of amplitude values compared to graft composites. The process of healing from a wound better postoperatively in the temporalis muscular graft fascia. Graft composites in terms of resistance to middle ear pressure are better than temporalis muscular graft fascia, so graft composites are not easily perforated. Researchers suggest that further research be done with a longer research time. Conducted research with a larger number of samples.

Ethical Clearance- Taken from Hasanuddin University ethical committee

Source of Funding- Self

Conflict of Interest - Nil

\section{References}

1. Fisch U et al. Tympanoplasty, Mastoidectomy, and Stapes Surgery. $2^{\text {nd }}$ edition. Annals of The Royal College of Surgeons of England. 2010; 92(1): 81.

2. Helmi A dkk. Bedah Otologi dan Neurootologi. Bedah Otologi dan Bedah Neurootologi Dasar, cetakan 2018. Jakarta: Penerbit Buku Kedokteran EGC.

3. Kolegium Ilmu Kesehatan THT Bedah Kepala Leher. Modul Peradangan Telinga Tengah. 2015; Jakarta: Kolegium Ilmu kesehatan THT Bedah Kepala Leher.

4. Cameron $\mathrm{C}$ et al. Endoscopic Lateral Cartilage Graft Tympanoplasty. International Journal of American Academy Otolaryngology Head and Neck Surgery Foundation. 2017; Vol. 4: 1-7.

5. Santhanakrishnan et al.. A Comparative Study of The Outcomes of Temporalis Fascia Graft Versus Tragal Perichondrium Graft in Type 1 Tympanoplasty in our Experience. International Journal of Otorhinolaryngology Head and Neck Surgery. 2017; Vol. 4: 60-62.

6. Veysel Y et al. Preparation and Placement of Cartilage Island Graft in Tympanoplasty. Brazilian Journal of Otorhinolaryngology Head and Neck Surgery. 2014; Vol. 6: 522-526.

7. Waleed A et al. Impact of Cartilage Graft Size on Success of Tympanoplasty. Brazilian Journal of Otorhinolaryngology Head and Neck Surgery. 2017; Vol. 83: 507-511

8. Chavan R.P et al. Overview of Tympanoplasty Techniques and Results. International Journal of Otorhinolaryngology and Head and Neck Surgery. 2017; Vol. 3: 170-175.

9. Kumar A et al. Comparative Study Between Result of Temporalis Muscle Fascia and Tragal Cartilage Perichondrium as a Graft Material in Type 1 Tympanoplasty. International Journal of Otorhinolaryngology and Head and Neck Surgery. 2018; Vol. 4: 565-568.

10. Owildan Wisudawan B, et al. Bioaerosol pollution in intensive-care unit of Dr. Wahidin Sudirohusodo Hospital Makassar: Morning and midday assessment. Enferm Clin. 2020. https://doi. org/10.1016/j.enfcli.2020.02.009

11. Tao Y et al. Comparison of Cartilage Graft and Fascia in Type

1 Tympanoplasty: Systematic Review and Metaanalysis. Journal of ACTA OTO- LARYNGOLOGICA. 2016; Vol. 136: 1084-1090.

12. Cummings W.C et al. Temporal Bone Anatomy, in Cummings Review of Otolaryngology. $7^{\text {th }}$ edition. Elsevier: Philadelphia. 2017. 